\title{
RESPONSES TO HYPERPOLARIZING CURRENTS IN CRAYFISH NERVE FIBERS DEPOLARIZED BY $\mathrm{KCl}$
}

\author{
Tadao Tomita, Teruaki Szaimi \\ AND Naoki ToIDA* \\ Department of Physiology, Faculty of Medicine, \\ Kyushu University, Fukuoka
}

When hyperpolarizing currents are applied to the nerve membrane previously depolarized by $\mathrm{KCl}$, the current-voltage relationship is not linear, i. e., the membrane potential being proportionally more increased than the current intensity. This process is time-dependent, i. e., the membrane potential gradually increases with time even if the current intensity is kept constant. This phenomenon is called "hyperpolarizing response" and it has been observed in various preparations by many investigators (in squid giant axon, SEGAL, 1958, MoORE, 1959, TASAKI, 1959, NARAHASHI, 1963 ; in toad Ranvier node, TASAKI, 1959 ; in frog Ranvier node, Mueller, 1958b, StÄMPfli, 1958, LÜTtGAU, 1960 ; in nerve cell, Hagiwara, Kusano \& SAITO, 1961). The spinal ganglion of the frog is also capable of producing a hyperpolarizing response, not only if the membrane is depolarized by excess $\mathrm{K}$ but also by Ca deficiency (KoKETsU \& KoyAmA, 1962). In some preparations hyperpolarizing responses have been observed without prior depolarization (in lobster muscle fiber, REUBEN, WERMAN \& GRUndFEST, 1961 ; in protozoa, CHANG, 1960 ; in dog heart muscle, CHANG \& Schmidt, 1960 ; in ascaris muscle Del Castillo, De Mello \& Morales, 1964, in mammalian smooth muscle, Kuriyama \& Tomita, 1965).

In the present paper the electrical responses to hyperpolarizing currents have been investigated in the single unmyelinated nerve fiber of the crayfish. Some of the results have been briefly reported (TomitA, SzAIMI \& ToIDA, 1961).

\section{METHOD}

Single moter nerve fibers were dissected from the meropodite segment of the walking limb of crayfish, Procambarus clarkii. The recording and stimulating techniques were the same as described previously (Tomita, Szaimi \& Toida, 1961; Wright \& Tomita, 1962). A nerve of $6-10 \mathrm{~mm}$ length was mounted in mineral oil with an Ag$\mathrm{AgCl}$ electrode at each end. The middle part of the fiber passed through a narrow

Received for publication September 25, 1965

* 富田忠雄, 細美照明, 問田㨁幹 
gap between two small tubes through which the test solution flowed. This served as the central electrode. Stimulating current was applied between an electrode at one end of the fiber and the central electrode, and recording was made between an electrode at the other end of the fiber and the central electrode. The experiments were carried out at room temperature of $15-20^{\circ} \mathrm{C}$.

\section{RESULTS}

1. Responses in the absence of conditioning inward current. FIG. 1 shows an example of the potentials which were produced across the membrane depolarized by isotonic $\mathrm{KCl}$ solution when square inward current palses of $50 \mathrm{msec}$ were applied. The current intensity was successively increased from A1 to B3. When the current intensity was raised above a critical level, the amplitude of the potential response increased with time at first slowly then sharply producing a step (A2). Stronger currents accelerated this process. This may be due to an increase of the membrane resistance and this has been called the "hyperpolarizing response" (TASAKI, 1959).

There was a limit to the amplitude of the potential difference which could be produced across the membrane by the inward current pulse. In response
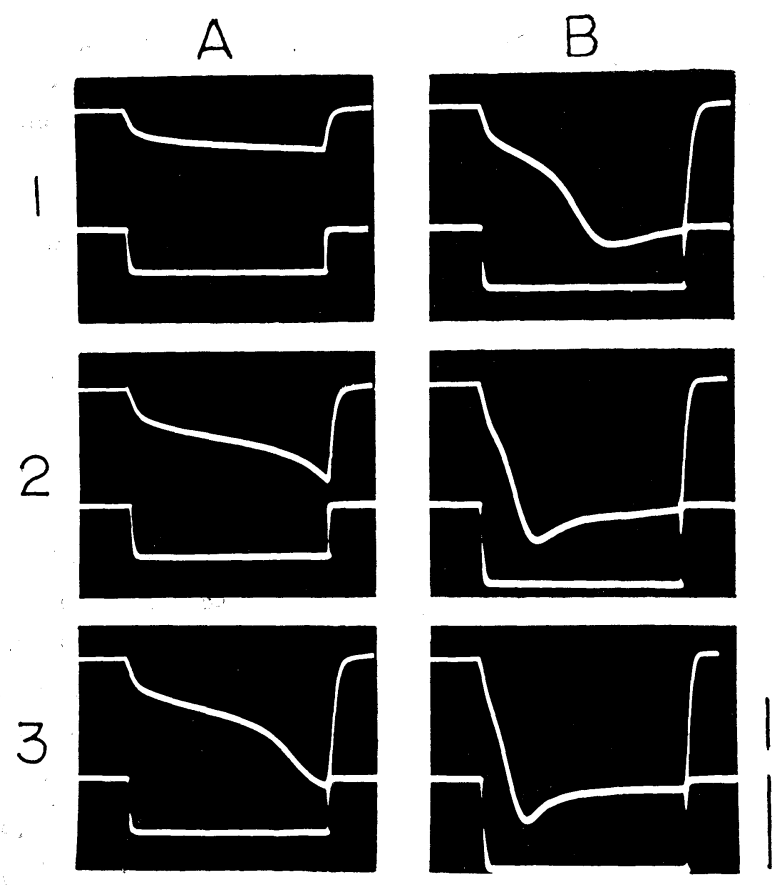

FIG. 1a. Electrical responses in the depolarized membrane with isotonic $\mathrm{KCl}$ solution to inward current pulses. The upper trace of each photograph shows the potential response and the lower trace shows the applied current. Upper bar, $2 \times 10^{-7} \mathrm{~A}$; lower bar, $50 \mathrm{mV}$ and time scale, $25 \mathrm{msec}$. 


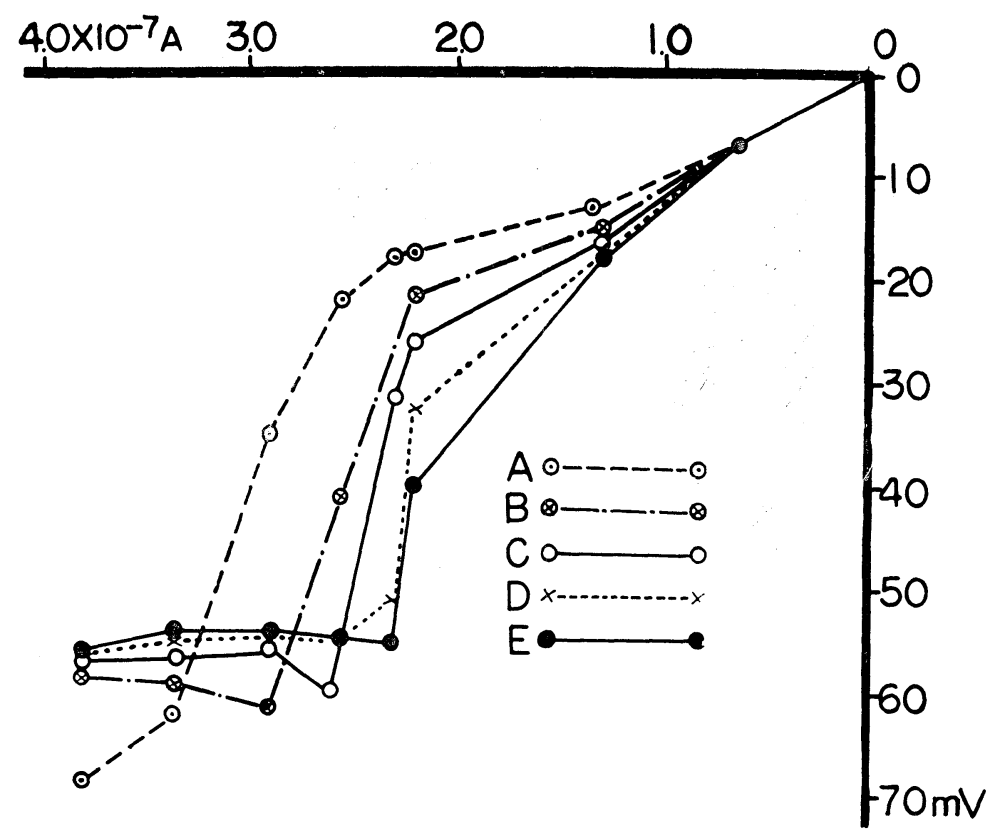

FIG. 1b. Current-voltage relationship taken from the same kind of responses as shown in FIG. 1a. Lines $\mathrm{A}, \mathrm{B}, \mathrm{C}, \mathrm{D}$ and $\mathrm{E}$ show the relationship $10,20,30,40$ and $50 \mathrm{msec}$ respectively after the onset of current pulse.

to a strong current the membrane potential reached the maximum after which the amplitude fell slightly producing a hyperpolarizing hump (B1 to B3 in FIG. 1a). The hump became sharper when the current intensity was further increased.

These situations are graphically shown in FIG. 1b. Each line shows the current-voltage relationship of the membrane at different time intervals from the onset of the current pulse. Lines A, B, C, D and E were obtained at 10, $20,30,40$ and $50 \mathrm{msec}$ respectively after the onset of the current pulses. There was a steep increase of the membrane potential above a certain current intensity (about $2 \times 10^{-7} \mathrm{~A}$ in this fiber). If the time interval from the onset of the current pulse was long, the membrane potential increased gradually with increasing current intensity (line E), and if the time interval was short, it remained at a low potential level even if a strong current pulse was applied, and it was increased rather steeply (line A). The change was steepest between 20 and $40 \mathrm{msec}$ after the onset of the current pulse (lines B and D). There was a limit (about $60 \mathrm{mV}$ inside more negative than the resting potential in this fiber) beyond which the membrane potential could not be continuously increased by applying a strong currents. This potential level was less negative after a longer time interval.

The electrical responses to inward currents of the membrane depolarized 
by $\mathrm{KCl}$ were different from fiber to fiber depending on its condition. In some fibers the steep increase of the membrane potential and the hump were very clear, but in others they were not. Recovery from the applied current pulse was slow so that repeated application within a short interval changed the response pattern.

Sometimes a repetitive response was observed especially during the initial stage of depolarization with $\mathrm{KCl}$ (FIG. 2). Similar responses have been seen in squid giant axon (NARAHASHI, 1963). In lobster muscle (REUBEN, et al., 1961), in protozoa (CHANG, 1960) and in ascaris muscle (Del Castillo, et al., 1964) such responses have also been produced but without prior depolarization with $\mathrm{KCl}$. Oscillatory behavior observed in the Ranvier node immersed in $\mathrm{KCl}$-rich solution (WRIGHT \& OOYAMA, 1962) seems to be a similar phenomenon although there is some difference in the shape.

FIG. 2a shows an example of such a response. After the responses were recorded in physiological solution (column A), the solution was replaced with isotonic $\mathrm{KCl}$ solution. The responses in column $\mathrm{B}, \mathrm{C}$ and $\mathrm{D}$ were taken 1,5 and $30 \mathrm{~min}$ respectively after the replacement. The repetitive hyperpolarizing

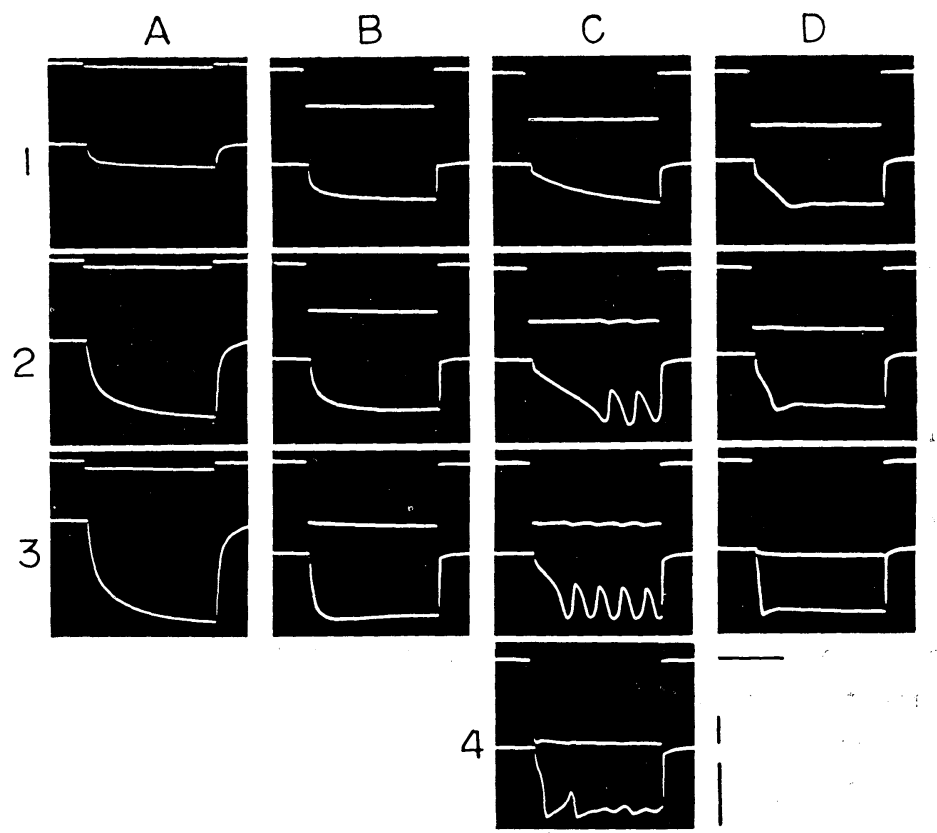

FIg. 2a. Electrical responses to inward current pulses. Column A, in physiological solution; $\mathrm{B}, \mathrm{C}$ and $\mathrm{D}, 1,5$ and $30 \mathrm{~min}$ respectively after the replacement of the solution with isotonic $\mathrm{KCI}$ solution. The upper trace of each photograph shows the applied current and the lower one shows the resulting potential. Upper bar, $10^{-7} \mathrm{~A}$; lower bar, $50 \mathrm{mV}$ and time scale, $25 \mathrm{msec}$. 


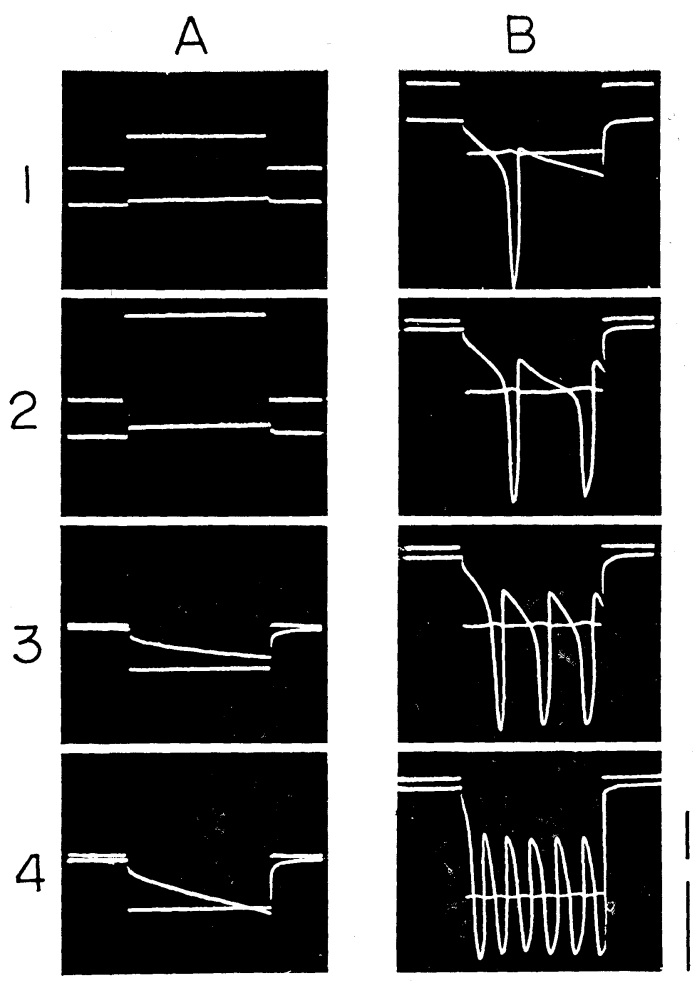

FIG. 2b. The repetitive hyperpolarizing response. $\mathrm{Al}$ and $\mathrm{A} 2$ show responses to outward current. Upper bar, $2 \times 10^{-7} \mathrm{~A}$; lower bar, $50 \mathrm{mV}$ and time scale, $25 \mathrm{msec}$.

response could be seen after the complete depolarization which usually occurred within $2 \mathrm{~min}$ ( $\mathrm{C} 2$ and $\mathrm{C} 3$ in FIG. 2a). When the current was too strong this response became irregular $(\mathrm{C} 4)$, and during the course of an experiment it became more difficult to produce the repetitive response (column $\mathrm{D}$ ).

FIG. 2b shows typical repetitive hyperpolarizing responses. A1 and A2 in the figure show the responses produced by the outward current. The membrane resistance was very low and there was no special response. When the inward current pulses were applied, however, the resulting potential difference across the membrane began to increase with time (A3 and 4) and a steep transient increase of the potential was suddenly produced at the threshold current intensity (B1). After reaching about $100 \mathrm{mV}$ in this fiber, it returned sharply back to the original potential level (about $20 \mathrm{mV}$ ). The characteristics of this response were similar to that of an action potential in many respects, though the polarity was opposite. As the intensity of the current pulse was increased, the latency became shorter and a second response was produced. Further increase of the current made the interval between the response shorter, 
the frequency of the repetitive response higher, and the amplitude of the response smaller, but it did not change the duration of the response (B2 to B4).

FIG. 3 shows the current-voltage relationship of the membrane in which the repetitive hyperpolarizing response was produced. Line 0 shows the relationship in physiological solution and lines 1,2, 3 and 4 respectively show the relationships 1,2, 3 and $4 \mathrm{~min}$ after the solution was replaced with isotonic $\mathrm{KCl}$ solution. In the membrane represented by line 1 , no repetitive response

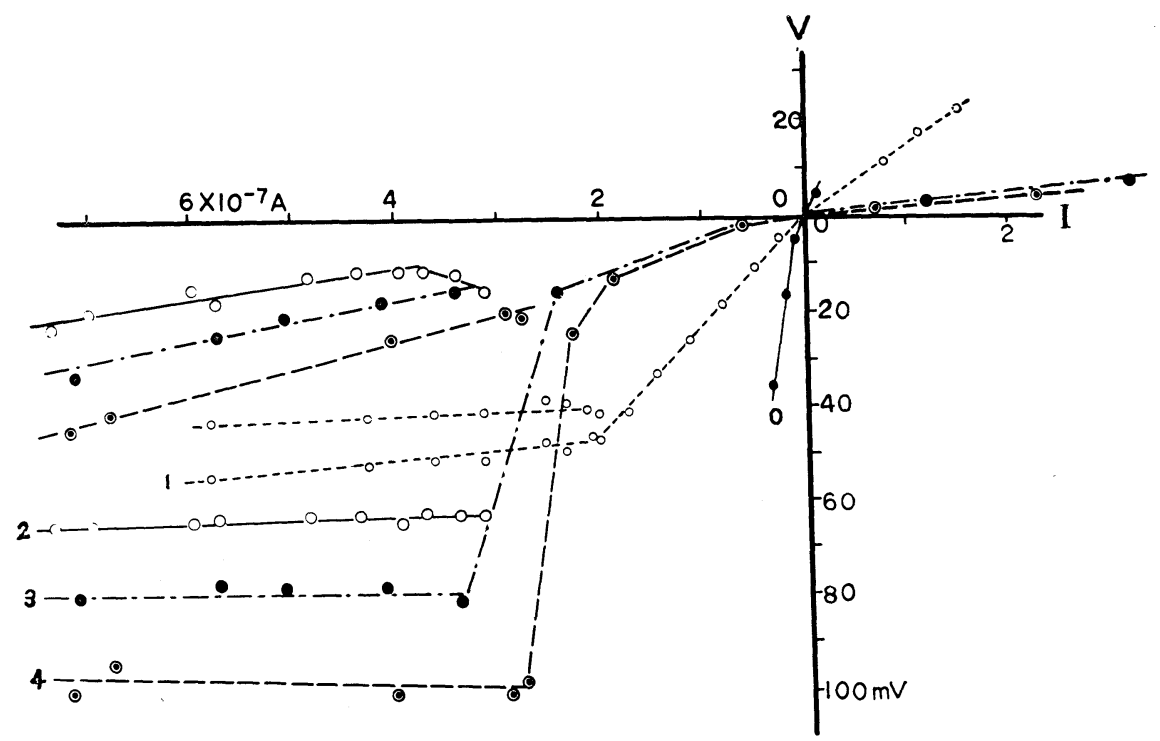

FIG. 3. Current-voltage relationship of the membrane in which the repetitive hyperpolarizing response was produced. Line 0 shows the relationship in physiological solution. Lines $1,2,3$ and 4 were taken $1,2,3$ and 4 min respectively after the solution was replaced with isotonic $\mathrm{KCl}$ solution. The upper of the paired lines having the same symbol shows the steady potential before or after the response, and the lower line shows the peak of the response. Line 2 shows the relationship of the membrane in which no repetitive hyperpolarizing response was observed yet.

could be produced yet. The upper of the paired lines having the same symbol shows the steady potential level and the lower line shows the peak of the hump. This current-voltage relationship is similar to that in FIG. 1b. Lines 2,3 and 4 show the relationship of the membrane in which the repetitive response was produced. The upper paired lines having the same symbol show the potential level just after the spike-like response and the lower lines show the peak of the response.

When the current intensity was increased above some critical value (about $2 \times 10^{-7} \mathrm{~A}$ in this fiber), the membrane potential increased steeply. Simultaneously the amplitude of the spike-like response also increased from line 2 to 4. The current-voltage relationship (upper lines) was almost the same before 
and just after the spike-like response. The peak of the spike-like response remained constant (lower lines) or only slightly decreased with increasing current intensity.

2. Responses in the presence of conditioning inward current. In FIG. 4, the membrane previously depolarized by $\mathrm{KCl}$ was repolarized with conditioning inward current of increasing intensity. During its application, another short inward current pulse was applied to the membrane (FIG. 4). When the inward current pulse was strong, there was a hyperpolarizing hump in the potential response as mentioned before (FIG. 1a and FIG. 4). This hump became slightly larger and sharper with increasing the conditioning inward current, but the absolute potential level following the hump remained almost constant. After the cessation of the current pulse there was a rebound (break-depolarization) beyond the level to which the membrane was polarized by the conditioning current. The break-depolarization then slowly returned back to the original potential level. The amplitude of the break-depolarization became larger with
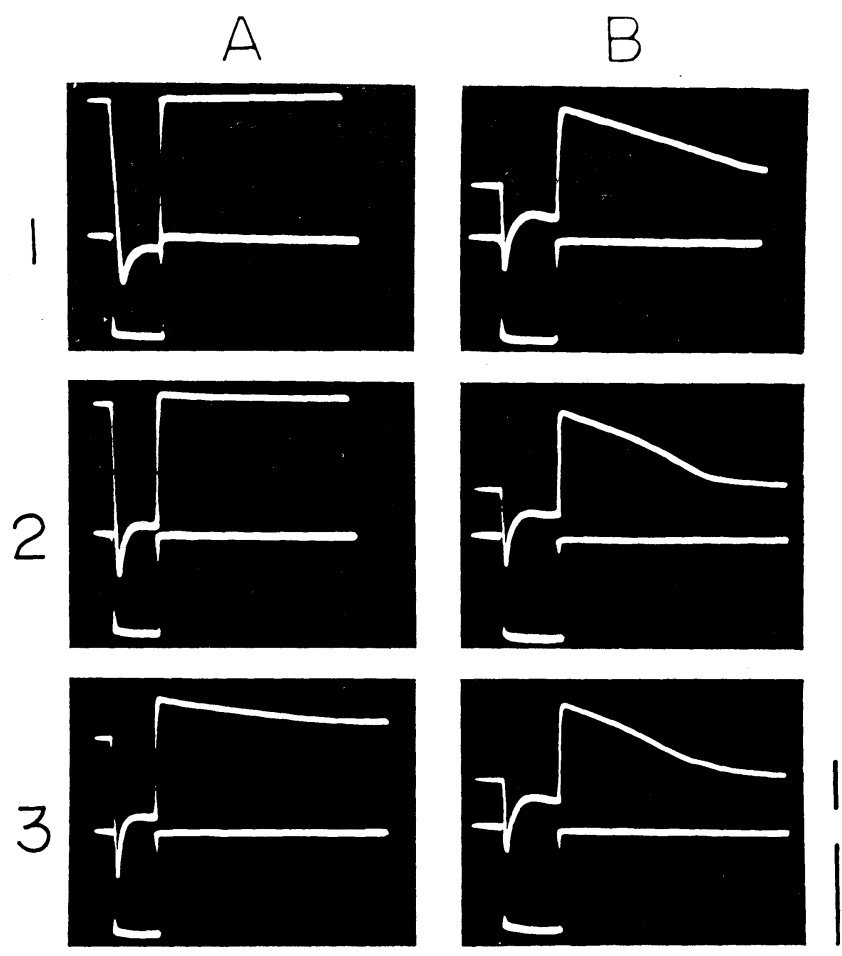

FIG. 4. The effect of conditioning hyperpolarizing current on the response to strong inward current pulse. Hyperpolarization was increased from A1 to B3. Upper bar, $10^{-7} \mathrm{~A}$, lower bar, $50 \mathrm{mV}$ and time scale, 100 msec. 
increasing membrane polarization. A similar response has been observed in the nerve cell (HAGIWARA et al., 1961). Usually no break-depolarization was observed without the conditioning inward current except in an incompletely depolarized membrane.

FIG. 5 shows responses to test pulses of the same intensity but three different durations. The break-depolarization became larger with increasing duration of the test pulse and its falling phase became faster with increasing of the membrane polarization.
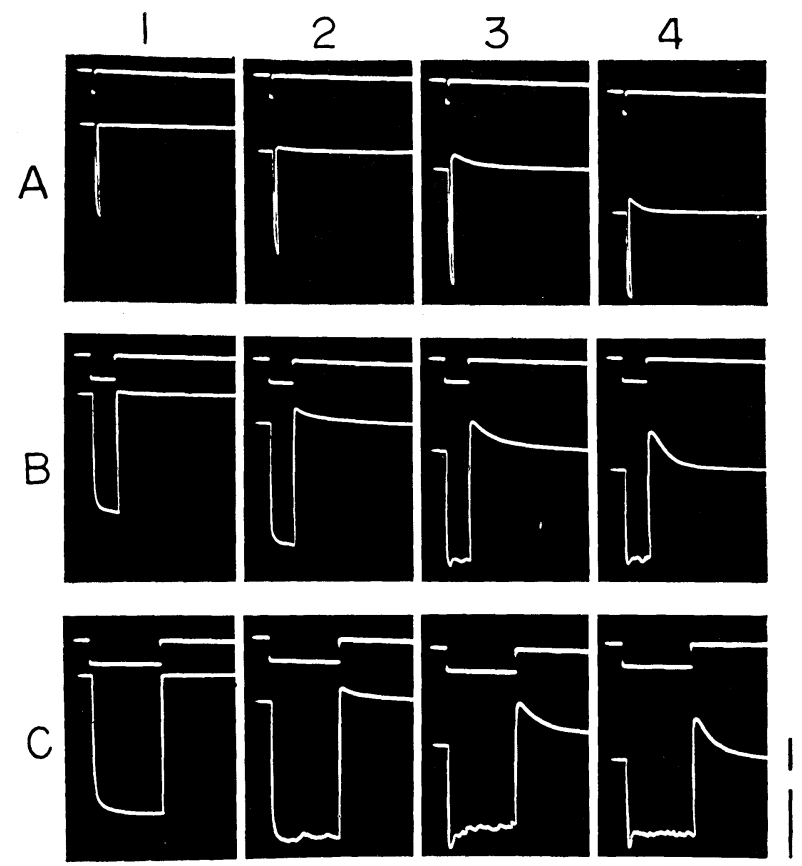

FIG. 5. Effects of conditioning hyperpolarization on the responses to inward current pulses with three different durations. Intensity of test current was kept constant. Calibrations: $1 \mathrm{C}^{-7} \mathrm{~A}, 50 \mathrm{mV}$ and $200 \mathrm{msec}$.

FIG. 6a shows the responses to a short current pulse with constant intensity applied during a long conditioning current pulse of increasing intensity. In row A, outward test pulses were applied. The amplitude of potential response to the outward test pulse increased with the membrane hyperpolarization by the long conditioning pulse. After the cessation of the depolarizing test pulse, the membrane potential returned back to the potential level in different ways, depending on the potential level which was determined by the conditioning current pulse. The rate of return to the original potential level was related to the rate of the response to the conditioning pulse, but was slightly faster. If the duration of the test pulse was increased, both processes 


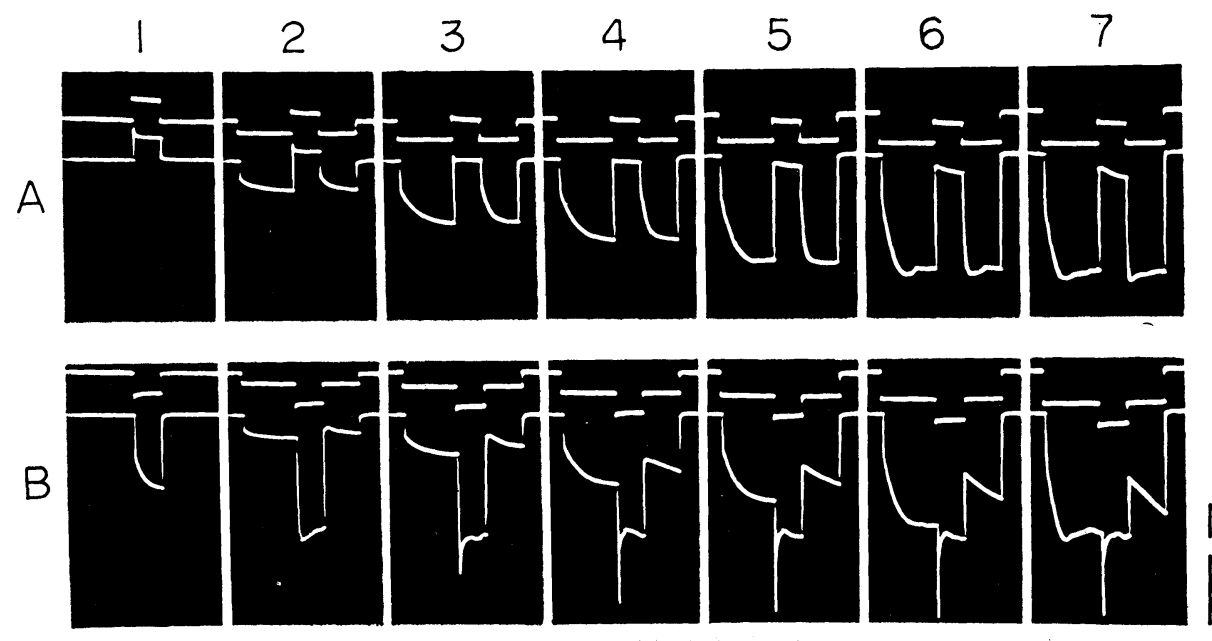

FIG. 6a. Responses to double current pulses. A : long inward current pulse with short outward pulse. B : long inward and short inward current pulses. Long pulses were made successively strong but short pulses were kept constant. Upper bar, $10^{-7} \mathrm{~A}$, lower bar, $50 \mathrm{mV}$ and time scale $100 \mathrm{msec}$.

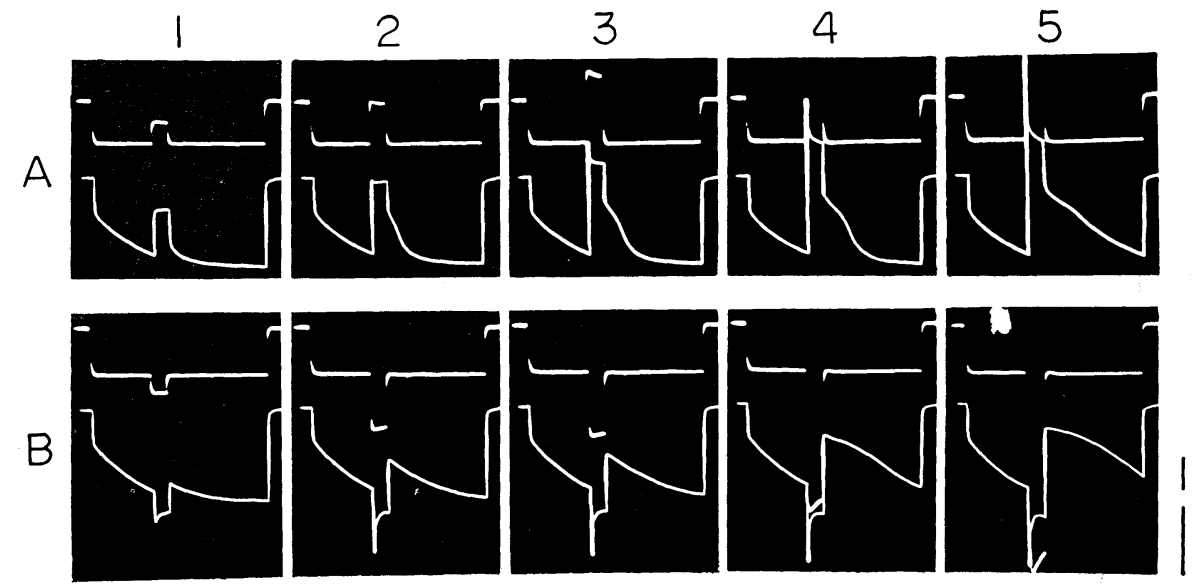

FIG. 6b. Responses to double current pulses. A: long inward current was kept constant and short outward pulse was successively increased. B: short pulse was inward. Calibrations: $10^{-7} \mathrm{~A}, 50 \mathrm{mV}$, and $100 \mathrm{msec}$.

became the same. At the limit beyond which the membrane potential could not be further increased irregular fluctuations were observed (A6 and 7 in FIG. 6a).

In row $\mathrm{B}$, both the test and the conditioning current pulses were applied in inward direction. The intensity of the test current pulse was kept constant 
while that of the conditioning pulse was increased. At a certain intensity a transient hyperpolarizing hump appeared (B2) and its amplitude increased, up to a limit, with increasing conditioning current intensity. Following the transient hump, the membrane potential remained at a constant level. After the cessation of the test pulse, there appeared the break-depolarization which was probably the same phenomenon as that seen in FIGs. 4 and 5. The time course of the falling phase of the break-depolarization was slower than that of the response to the conditioning current pulse.

In FIG. 6b, the intensity of the conditioning current pulse was kept constant, while the intensity of the test current pulse was gradually increased. The time course of the falling phase of the response to the test current pulse became slower with increasing intensity.

In FIG. 7a, short inward current pulse were applied to the membrane while the membrane was repolarized by a constant inward current. A breakdepolarization was observed, the amplitude of which was increased with increasing test pulse. Beyond a certain test pulse intensity a prolonged depolarizing response was produced in an all-or-none manner (B2). The afterpotential following the prolonged depolarizing response seemed to be a
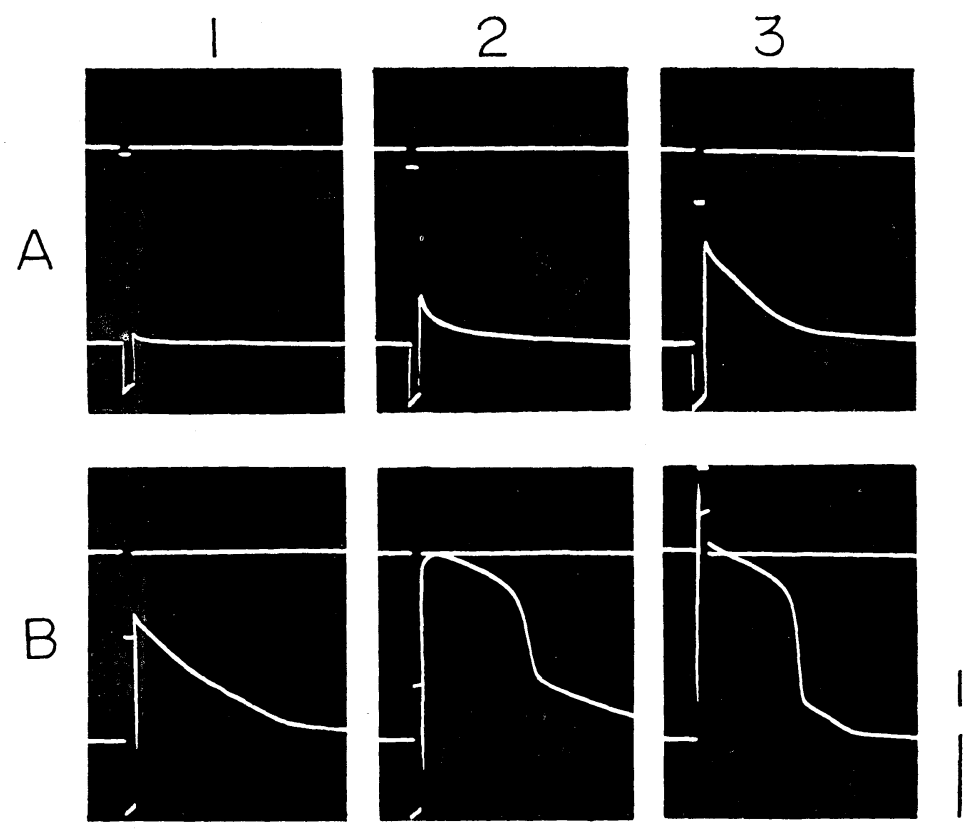

FIG. 7a. Responses to inward current pulses in the membrane which was hyperpolarized with conditioning hyperpolarizing current. Intensity was successively increased from $\mathrm{A} 1$ to $\mathrm{B} 2$. B3: response to outward cur. rent pulse. Calibrations : $10^{-7} \mathrm{~A}, 50 \mathrm{mV}$, and $500 \mathrm{msec}$. 

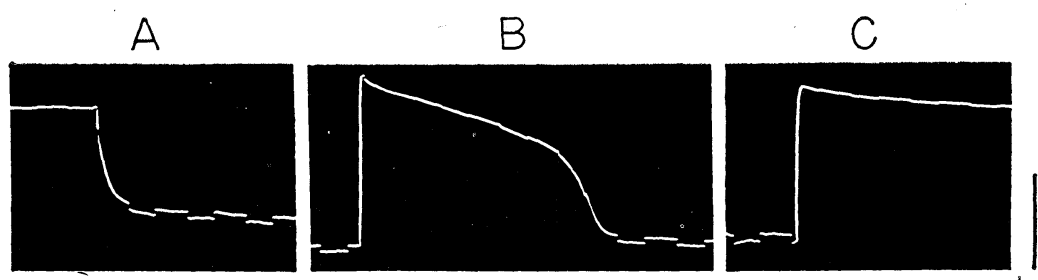

FIG. 7b. In A, conditioning hyperpolarizing current was applied; in B, the slow depolarizing response was produced by short outward current pulse while hyperpolarizing conditioning current was still continued; and in $\mathrm{C}$, conditioning current was withdrawn. In order to show the change in the membrane resistance small constant current pulses were applied throughout. Calibrations : $50 \mathrm{mV}$ and $1 \mathrm{sec}$.

remaining part of the break-depolarization since it had the same time course. It was found that the break-depolarization could not be abolished by an inward current pulse but the prolonged depolarizing response was easily abolished (MUELler, 1958b; OOYAMA \& Wright, 1962). The same prolonged
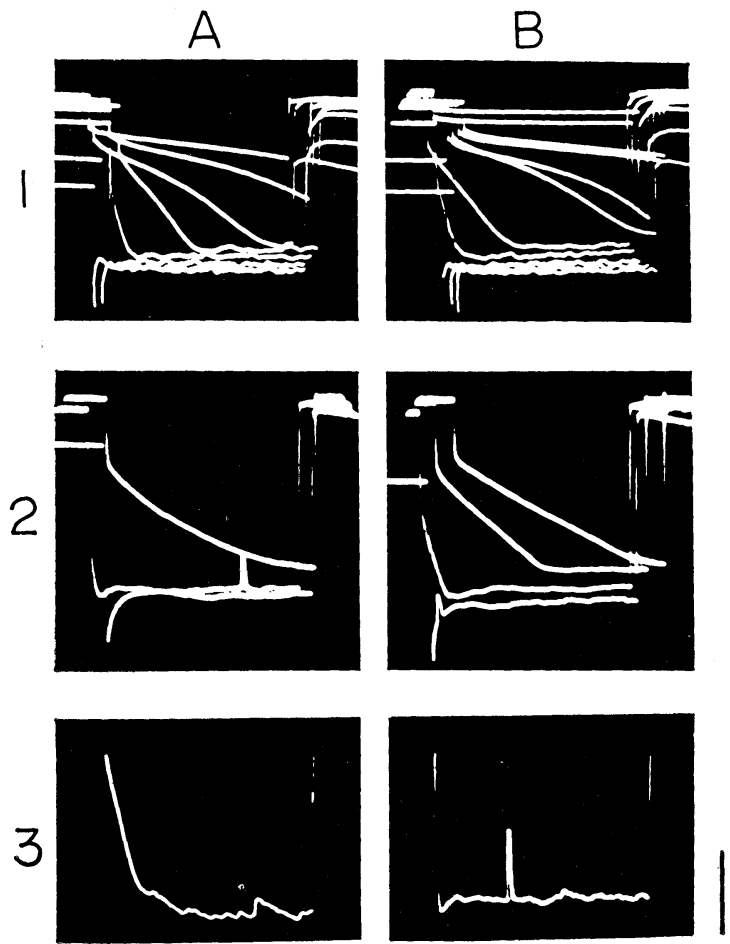

FIG. 8. Irregular fluctuations of the membrane potential during the strong hyperpolarization. Spike-like response can be seen in row 2 and B3. Calibrations: $50 \mathrm{mV}$ ( $25 \mathrm{mV}$ for row 3) and $25 \mathrm{msec}$. 
depolarizing response was easily produced by a much weaker outward current pulse, as observed in many preparations (LÜTTGAU, 1960; MUELleR, 1958a ; OOYAMA \& WRIGHT, 1962 ; TASAKI, 1959; Wright \& TOMITA, 1962).

During the experiment shown in FIG. 7b small square current pulses of the same intensity were continuously applied in order to show the change of the membrane resistance. (A) shows the potential response produced by the onset of the conditioning constant current, (B) the response to short outward current pulse during the conditioning hyperpolarization, and $(C)$ the response to cessation of the conditioning current.

FIG. 8 shows the irregular fluctuation of the membrane potential produced by very strong inward currents. Sometimes a small spike-like response was observed on the fluctuating membrane potential (A2, B2 and B3). To show these response clearly, the amplification in row 3 was doubled.

\section{DISCUSSION}

1. Hyperpolarizing responses. Membranes which produce a hyperpolarizing response, and a prolonged depolarizing response under conditioning hyperpolarization seem to have a common feature, i.e. a low membrane resistance and a characteristic change of the membrane resistance when inward current is applied. Some tissues produce a hyperpolarizing response in normal condition. Others, including the crustacean nerve, require previous depolarization of the membrane with high external potassium.

When the hyperpolarizing response is produced in an all-or-none manner or in repetitive form the current-voltage relationship is steep and almost parallel to the potential axis (see FIG. 3). In this region only a small increase of current is required beyond the critical intensity to produce a large potential change indicating that there might be a negative resistance region (MOORE, 1959). The rate in the increase of the resistance may be an important factor.

The hyperpolarizing response may be explained by potassium-activation (increase of potassium conductance) and potassium-inactivation (decrease of potassium conductance) processes which are able to operate independently from and much slower than, the sodium-carrier process (GRUNDFEST, 1961; OOYAMA \& Wright, 1962; Wright \& TOMITA, 1962: HASHIMURA, 1962).

2. Anode-break-depolarization. A considerable increase in the membrane resistance was brought about by the process of hyperpolarization, while a decrease in the resistance was observed at the peak of the spike-like response (CHANG, 1961), or of the hump of the hyperpolarizing response (TASAKI, 1959). Specially, change in dynamic (or slope) resistance is very pronounced and might be one of the reasons for a termination of the transient response.

The slope of the lines showing the current-voltage relationship of the membrane during or at the peak of the hyperpolarizing response is almost 
parallel to the current axis (FIG. $1 \mathrm{~b}$ and FIG. 3), indicating that the dynamic resistance of the membrane is very low (REUBEN, et al., 1961). This process might correspond to the breakdown phenomenon of the membrane (HodGKIN, 1947 ; FATT \& KATZ, 1951).

The decrease of the dynamic resistance of the membrane due to very strong inward current is usually accompanied by irregular fluctuations of the membrane potential as seen in FIGS. 5 and 8. A similar phenomenon has been observed in the Ranvier node in normal solution (OOYAMA \& WRIGHT, 1961).

FIG. 9 illustrates schematically an explanation of the production of the break-depolarization. When the depolarized membrane is hyperpolarized by current, the membrane resistance starts to increase at a potential level I and gradually continues to rise towards a potential level II producing the hyperpolarizing response. The time course of this process depends on the condition of the fiber. However, beyond the potential level II the resistance is so much decreased that the potential, which is the product of resistance $\left(R_{1}\right)$ and current $\left(\mathrm{I}_{1}\right)$, becomes stable.
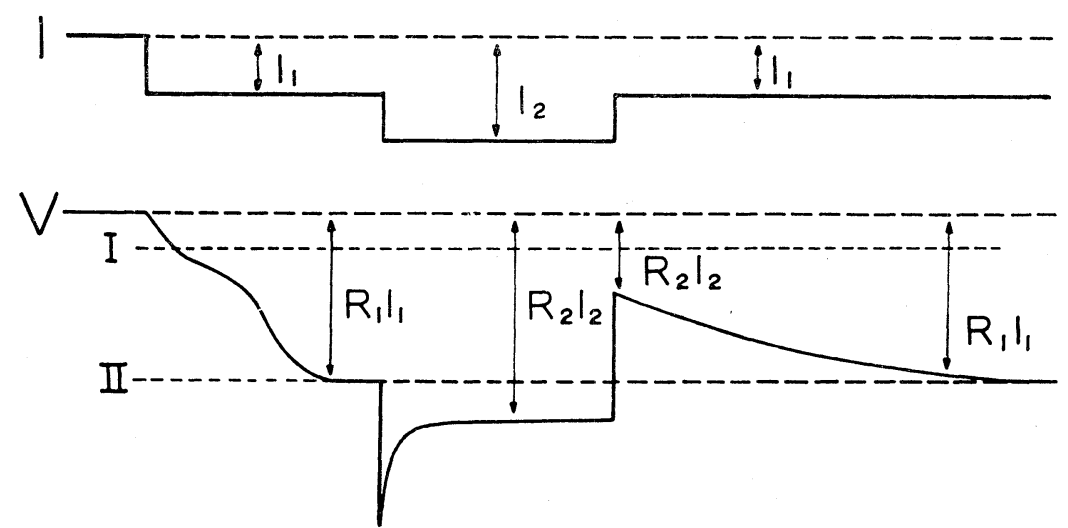

FIG. 9. Schematic drawing of hyperpolarizing response, hyperpolarizing hump and break-depolarization. Upper part (I) shows applied current. Lower part $(\mathrm{V})$ shows the electrical response in $\mathrm{KCl}$ depolarized membrane. For explanation see text.

When another inward current pulse is superimposed on the conditioning current inward which keeps the membrane at the potential level II, the resistance is rapidly decreased from $R_{1}$ to $R_{2}$ producing a hyperpolarizing hump. As the resistance returns very slowly from $R_{2}$ to $R_{1}$ after the cessation of the current pulse, the break-depolarization is produced.

If $\mathrm{R}_{2} \times \mathrm{I}_{1}$ is small, the break-depolarization is large. If the break-depolarization approaches the level I some all-or-none activity is produced in the membrane (potassium-activation). In other words, the break-depolarization 
itself stimulates the membrane to produce the prolonged depolarizing response seen in FIG. 7a. The falling phase of the prolonged depolarizing response is probably due to the same process as the hyperpolarizing response.

\section{SUMMARY}

1. The electrical response to inward current pulses were studied in the membrane of a single nerve fiber of the crayfish, Procambarus clarkii, depolarized by $\mathrm{KCl}$.

2. The hyperpolarizing response was observed at a critical membrane potential producing a hump or repetitive and spike-like potential.

3. Cessation of a second inward current pulse during conditioning hyperpolarization caused break-depolarization and, at a critical intensity, a slow depolarizing response.

4. The electrical responses observed in this membrane could be mostly explained in terms of changes of the membrane resistance.

\section{REFERENCES}

1) Chang, J. J. Electrophysiological studies of a non-luminescent form of dinoflagellate, Noctiluca miliaris. J. cell. comp. Physiol. 56 : 33-42, 1960.

2) Chang, J.J. And Schmidt, R. G. Prolonged action potentials and regenerative hyperpolarizing responses in Purkinje fibers of mammalian heart. Pflüg. Arch. ges. Physiol. 272 : 127-141, 1960.

3) Del Castillo, J., De Mollo, W.C. And Morales, T. Hyperpolarizing action potentials recorded from the oesophagus of Ascaris lumbricoides. Nature, 203 : 530-531, 1964.

4) Fatt, P. And Katz, B. An analysis of the end-plate potential recorded with an intracellular electrode. J. Physiol. 115: 320-370, 1951.

5) Grundfest, H. Ionic mechanisms in electrogenesis. Ann. N.Y. Acad. Sci. 94 : 405-457, 1961.

6) Hagiwara, S., Kusano, K. And Saito, N. Membrane changes of Onchidium nerve cell in potassium-rich media. J. Physiol. 155: 470-489, 1961.

7) Hashimura, S. On the two components of the action potential from single nodes of Ranvier in potassium-rich media. Jap. J. Physiol. 12: 447-459, 1962.

8) Hodgkin, A.L. The membrane resistance of a non-medullated nerve fibre. $J$. Physiol. 106 : 305-318, 1947.

9) Koketsu, K. And Koyama, I. Membrane resistances of frog's spinal ganglion cells in calcium-free solutions. J. Physiol. $163: 1-12,1962$.

10) Kuriyama, H. And Tomita, T. The responses of single smooth muscle cells of guinea-pig taenia coli to intracellularly applied currents, and their effect on the spontaneous electrical activity. J. Physiol. 178: 270-289, 1965.

11) Lüttgau, H. C. Das Kalium-Transportsystem am Ranvierknoten isolierter markhaltiger Nervenfasern. Puflüg. Arch. ges. Physiol. 271: 613-633, 1960.

12) Moore, J.W. Excitation of the squid axon membrane in isosmotic potassium chloride. Nature, 183 : 265-266, 1959.

13) Mueller, P. Prolonged action potentials from single nodes of Ranvier. J. gen. Physiol. 42: 137-162, 1958a. 
14) Mueller, P. Effects of external currents on duration and amplitude of normal and prolonged action potentials from single nodes of Ranvier. J. gen. Physiol. 42 : 163-191, 1958b.

15) NARAHASHi T. Dependence of resting and action potentials on internal potassium in perfused squid axons. J. Physiol. 169: 91-115, 1963.

16) OOYAmA, H. AND WRight, E. B. Anode break excitation on single Ranvier node: of frog nerve. Amer. J. Physiol. 200: 209-218, 1961.

17) Ooyama, H. AND WRight, E.B. Activity of potassium mechanism in single Ranvier node during excitation. J. Neurophysiol. 25: 67-93, 1962.

18) Reuben, J. P., Werman, R. And Grundfest, H. The ionic mechanisms of hyperpolarizing responses in lobster muscle fibers. J. gen. Physiol. 45: 243-265, 1961.

19) Segal, J.R. An anodal threshold phenomenon in the squid giant axon. Nature, 182: 1370, 1958.

20) Stämpfli, R. Die Strom-Spannungs-Charakteristik des erregbaren Membran eines. einzelnen Schnürrings und ihre Abhängigkeit von der Ionenkonzentration. Helv. physiol. acta. $16: 127-145,1958$.

21) TASAKI, T. Demonstration of two stable states of the nerve membrane in potassium-rich media. J. Physiol. 148 : 306-331, 1959.

22) Tomita, T., Szaimi, T. ANd Toida, N. Repetitive hyperpolarizing response of the nerve fibre of crayfish. Nature, 190: 271-272, 1961.

23) Wright, E.B. And Ooyama, H. Role of cations, potassium, calcium and sodium during excitation of frog single nerve fiber. J. Neurophysiol. 25: 94-109, 1962.

24) Wright, E.B. ANd Tomita, T. Separation of sodium and potassium ion carrier system in crustacean motor axon. Amer. J. Physiol. 202: 856-864, 1962. 